\title{
AC 2012-3951: WEAVING SUSTAINABILITY INTO UNDERGRADUATE ENGINEERING EDUCATION THROUGH INNOVATIVE PEDAGOGICAL METHODS: A STUDENT'S PERSPECTIVE
}

\author{
Miss Sarah Kathryn Bauer, Rowan University
}

Sarah K. Bauer is a junior civil and environmental engineering undergraduate student studying at the College of Engineering of Rowan University with a minor in mathematics. Bauer is a part of Rowan University's Bantivoglio Honors concentration. She works as both a civil and environmental engineering ontern and an environmental engineering Research Assistant for the College of Engineering at Rowan University. She is President of Rowan University's Student Chapter of the Society of Women Engineers and Secretary of Rowan University's Student Chapter of the American Society of Civil Engineers. Sarah is also the recipient of the Fall 2011 and Fall 2012 Bantivoglio Honors Concentration Research Fellowship.

\section{Miss Andrea Rose McFarland, Rowan University}

Andrea R. McFarland is a sophomore undergraduate student studying civil and environmental engineering through the College of Engineering at Rowan University. McFarland is part of Rowan University's Bantivoglio honors concentration. She is the recipient of the Spring 2012 and Fall 2012 Bantivoglio Honors Concentration Research Fellowship. McFarland works as both a civil and environmental engineering intern and an environmental engineering Research Assistant at Rowan University's College of Engineering. This past summer, McFarland worked as an environmental engineering assistant at PTP consulting. She is the vice president of Rowan University's student chapter of Engineers Without Borders (EWB). Through EWB, McFarland traveled to Africa in Jan, 2012 to design and implement water retrival systems for eight villages.

\section{Dr. Mary M. Staehle, Rowan University}

Mary Staehle is an Assistant Professor of chemical engineering at Rowan University. Before joining the faculty at Rowan, Staehle worked at the Daniel Baugh Institute for Functional Genomics and Computational Biology at Thomas Jefferson University. She received her Ph.D. from the University of Delaware in 2010. Her research is in the area of biological control systems, specifically neural regeneration. Staehle is also particularly interested in chemical, bio-, and biomedical engineering education.

Dr. Kauser Jahan, Rowan University 


\title{
Weaving Sustainability into Undergraduate Engineering Education through Innovative Pedagogical Methods: A Student's Perspective
}

\begin{abstract}
Engineering educators are continually striving to develop teaching tools that engage students' imaginations, provide a platform for integrating modern technology into the undergraduate curriculum, and address pressing societal needs. In recent years, spurred by the declining condition of the environment, engineering educators have begun to incorporate concepts of green engineering and sustainability into undergraduate education. Through the perspectives of undergraduate students who are enrolled in the newly developed, environmentally conscious curriculum of Rowan University's College of Engineering, early experiences in engineering education will be showcased.

The hallmark of Rowan University's Engineering program is its Engineering Clinic: a required eight-semester sequence for engineering majors that brings real-world engineering into the classroom through interdisciplinary, project-based learning. Undergraduate students are engaged in the scientific discovery process through these stimulating activities while they are concurrently introduced to multidisciplinary engineering principles from Chemical, Mechanical, Electrical and Computer, and Civil and Environmental Engineering. Engineering design, heavily emphasized in the Freshman and Sophomore Engineering Clinic courses, has expanded beyond the physical development of ideas to now incorporate sustainable practice. The Clinic sequence highlights several modules that require students to develop imaginative solutions to environmental issues, such as fuel shortages and the need for alternative energy. Students address these issues directly through such projects as deriving biofuels from microalgal species and designing and constructing wind turbines and solar panels. These topics and experiences bring tremendous strength to a student's knowledge of and appreciation for sustainable engineering. Through Rowan University's College of Engineering Clinic sequence, engineers of the future are gaining a fundamental understanding of their role in the design and analysis of complex interacting systems, as well as discovering the importance of incorporating sustainability into engineering practice.
\end{abstract}

\section{Introduction}

The concept of sustainability has been introduced over the last several decades in order to address the causes and effects of humanity's increasing impact on the environment. Atmospheric carbon dioxide concentrations have been steadily increasing due to the burning of fossil fuels and deforestation in the past decade, and estimations indicate that more than 20 billion tons of carbon per year will be added to the atmosphere over the next 45 years as countries worldwide continue to industrialize ${ }^{1}$. Furthermore, according to the Energy Information Administration, the total world energy consumption is projected to increase by 50 percent between 2005 and $2030^{1}$. These are sobering projections, and as such, the challenge for this generation of scientists and engineers is to develop cost effective, environmentally-friendly sources of energy to meet the world's growing energy needs, along with technologies that also reverse carbon dioxide emissions. A cleaner energy future depends on the development of 
sustainable energy sources that are technically feasible, economically viable, and protective of human health and welfare.

Sustainability is defined as the design of human and industrial systems that ensure that the use of natural resources does not jeopardize or diminish current or future quality of life ${ }^{2}$. Sustainable practices leading to appropriately designed products, and technological systems and services are critical to environmental and social performance across a globalizing economy. Sustainable engineering is a conceptual and practical challenge to all engineering disciplines. Although the profession has experience with environmental dimensions of engineering that in some cases are quite deep, extending the existing body of practice to sustainable engineering by including social and cultural domains is a significant challenge. This requires engineers of the twenty-first century to have creative problem-solving skills and to evaluate the implications of their solutions beyond their immediate technical context ${ }^{2}$.

Despite an awareness of the importance of sustainability, when a selection of undergraduate engineering students across the country was asked to define "sustainable engineering," the answers included a broad spectrum of both realistic and vague statements of sustainable engineering principles ${ }^{2}$. Answers included extending the life of products as long as possible and minimizing energy and materials usage. Other answers implied that engineers must contribute to a sustainable world. However, some students were unable to provide any definition. This indicates that there is a considerable need for increased knowledge and awareness of the issues surrounding sustainable development and an understanding of how societal and industrial actions impact the environment and future generations. With the pressures of rising population and declining resources, engineers will be called upon to design more economically-efficient systems and technologies to deal with the ever-increasing uncertainty, and to consider the social and economic impacts of engineering choices in both a national and global setting ${ }^{2}$. Therefore, an introduction to sustainability concepts must be included in the undergraduate engineering curriculum. Such concepts include an understanding of the interdependence of major systems, an understanding of the needs and rights of future generations, an understanding of the value of diversity, an appreciation of the need for precaution, and an awareness of the Earth's carrying capacity $^{3}$. The undergraduate engineering curriculum of Rowan University's College of Engineering has been molded to introduce undergraduate students to these issues and to provide an introduction to sustainable engineering through interdisciplinary project-based learning.

\section{Rowan University's Engineering Clinic Sequence}

The signature component of Rowan University's College of Engineering curriculum is its Engineering Clinic sequence. The Clinic sequence provides a hands-on, team-oriented approach to a multidisciplinary, four year education. The sequence also provides a blueprint for classroom, laboratory, and work experiences. The key objectives of the Engineering Clinic sequence include:

- Creating multidisciplinary experiences through collaborative laboratories and coursework;

- Incorporating modern technologies and contemporary issues throughout the curricula;

- Creating continuous opportunities for technical writing and communication; and 
- Emphasizing hands-on, open-ended problem solving, including undergraduate research ${ }^{4}$.

Every engineering student at Rowan University takes an Engineering Clinic class each semester. In these courses, students and faculty from all four engineering departments in the Rowan University College of Engineering (Chemical Engineering, Civil and Environmental Engineering, Electrical and Computer Engineering, and Mechanical Engineering) work side-byside on laboratory experiments, real-world design projects, and fundamental research. The solutions of these problems require not only proficiency in the technical principles, but, of equal importance, they require a mastery of written and oral communication skills and the ability to work as part of a multidisciplinary team. To help students achieve these curricular objectives, each Engineering Clinic course involves team building, hands-on activities, technical report writing, and oral presentations. The underlying concepts of engineering design pervade throughout all eight semesters ${ }^{4}$. However, as shown in Table 1, each Clinic course has a specific theme and emphasizes specific topics ${ }^{4}$. Inside of these overarching objectives, the engineering faculty at Rowan University have developed a variety of projects of innovative pedagogy that focus on sustainable engineering at each level of Engineering Clinic.

\begin{tabular}{|c|c|c|}
\hline \multicolumn{2}{|c|}{ Table 1: Overview of the Course Content in the Eight-Semester Engineering Clinic } \\
Sequence
\end{tabular}

Sustainability in the Freshman Engineering Clinic

Freshman Engineering Clinic sections are randomly assigned, and each section typically contains a multidisciplinary group of 20-30 students. The fall semester is focused on engineering measurements, introductory engineering principles, and transitioning to the university environment. Common lecture topics include: unit conversion, note taking, problem solving, engineering judgment, and ethics. Laboratory components in the fall semester expose students to the four major engineering disciplines offered at Rowan University. Ideally, students in each section perform three laboratory activities in each discipline, although each individual instructor may select experiments in alternate proportions. Examples of laboratory activities that Freshman Engineering Clinic I students have completed include: fluidized bed polymer coating, wind turbine construction, circuit building, and manufacturing products from 3D drawings. 
The theme of Freshman Engineering Clinic II is reverse engineering. A sample Freshman Clinic II syllabus is available in Appendix A. Together, the class works through engineering projects focusing on introductory engineering concepts and reverse engineering, as listed in Table $1^{4}$.

Reverse engineering involves the process of improving a product through disassembly and systematic testing. Depending on the section, students in Freshman Clinic II reverse engineer automatic coffee makers, flashlights, electric toothbrushes, radios, beer brewers, or portable water filters ${ }^{4}$. In each reverse engineering project, one of the desired "improvements" is to make the product more energy-efficient. This provides an opportunity to include sustainable engineering in the Freshman Engineering Clinic curriculum. During weekly lectures and throughout the project-based learning experiences, it is emphasized that making a product energy-efficient is beneficial to society because there are less detrimental environmental effects. It is also stressed that this is beneficial to the consumer, because it is more costeffective.

Other projects in Freshman Engineering Clinic have had more direct ties to sustainable engineering. For example, some students extracted biodiesel from restaurants' discarded cooking oil, others calculated the carbon footprint of an average American home, and other students researched and tested solar-based power systems. These projects focus on the technologies predicted to be important in developing sustainable engineering solutions.

\section{$\underline{\text { Solar Panel Development }}$}

The solar panel project at Rowan University requires students to research solar panels and test a solar-based power system to determine how much energy can be generated. Students are taught about solar power through listening to faculty lectures and conducting personal literature reviews on solar panel development. As technologies are improving, solar power is gaining ground and becoming a more economical engineering choice. Undergraduate students have the chance to explore these technologies by building their own solar panel mounts for mounting a universityowned solar panel and conduct energy testing to see how efficient they can make their products. Throughout the experiment, students continually strive to use minimal materials. The economical facet of sustainability is stressed when the teams are graded on the cost of their solar panel mount design. Figure 1 shows an undergraduate student at Rowan University building his solar panel mount. The final product attached to a solar panel is shown in Figures 2 and 3. During upper-level Clinic courses, students also have the opportunity to continue studying solar energy. 


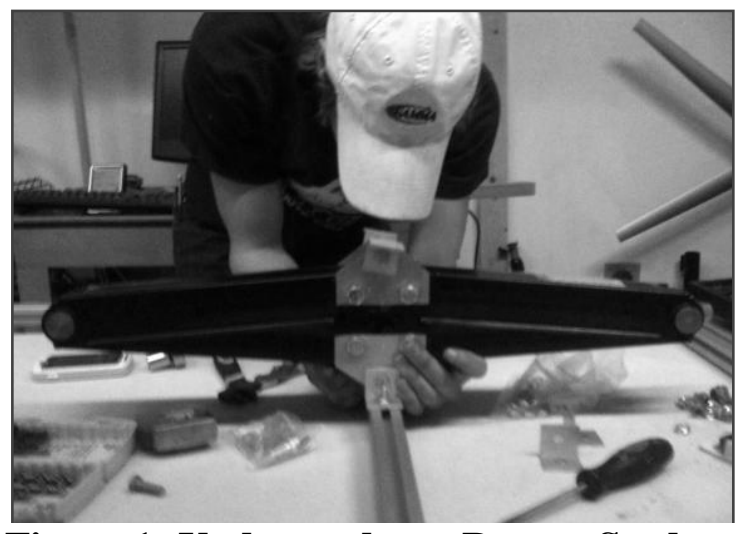

Figure 1: Undergraduate Rowan Student Building a Solar Panel Mount ${ }^{7}$

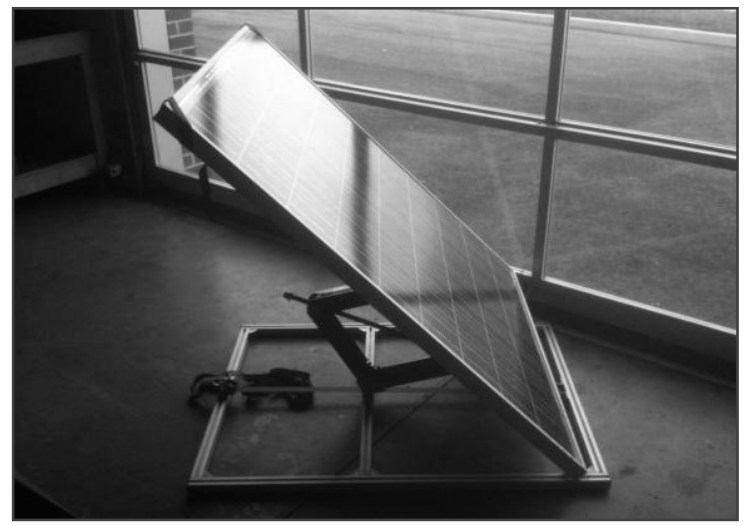

Figure 2: Solar Panel Mount Built by Undergraduate Rowan Students ${ }^{7}$

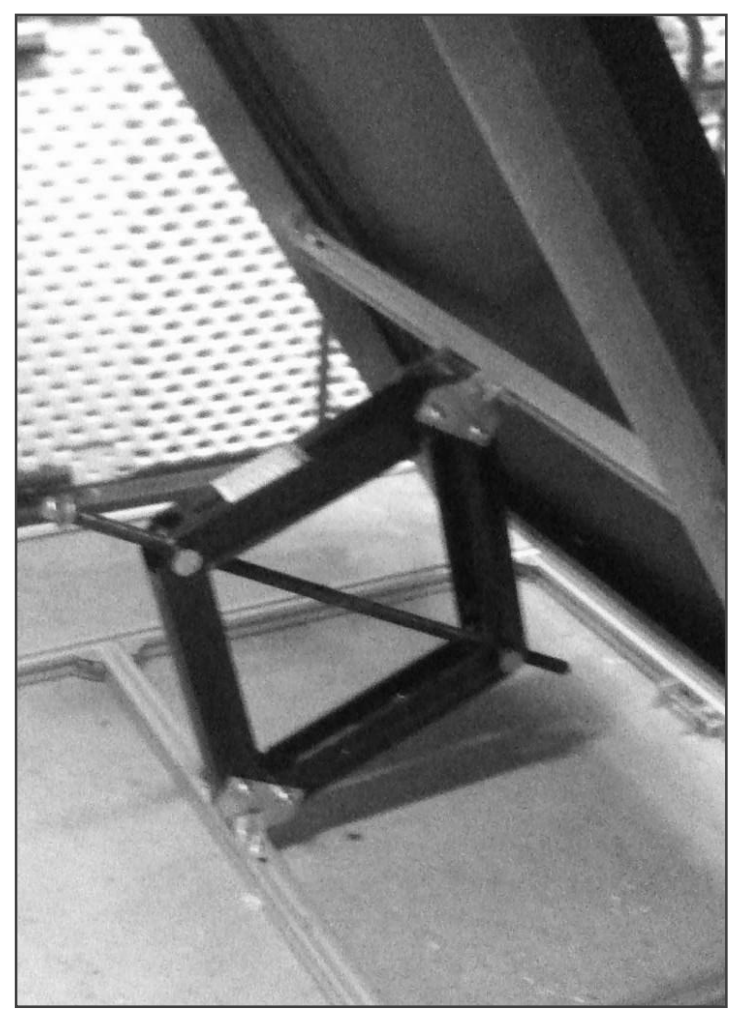

Figure 3: Undergraduate Rowan Student Handmade Solar Panel Mount ${ }^{7}$

\section{$\underline{\text { Environmental Ethics }}$}

Being conscious of the environment is crucial, but Rowan University's Engineering Clinic sequence recognizes there is also a social dimension of sustainability. Every engineer has a responsibility to conduct themselves and their projects in an ethical manner that does not threaten the well-being of society or the environment. In the Clinic sequence, proper procedures are stressed at the beginning of experiments so that every experiment is conducted in an ethical manner.

For example, in some sections of Freshman Clinic II, students are exposed to ethics in an engaging and entertaining way. The class is split into groups to encourage interdisciplinary team dynamics, as is stressed in each Clinic section throughout the Engineering Clinic sequence. Each team is required to pick an ethically charged film, watch it together, and then present the details of the ethical plot dilemma and how they as engineers would handle the problem. One film option is the 1999 film "Bhopal Express" which follows a young couple through the disaster of the Bhopal gas tragedy. Another film choice, "A Civil Action", is a 1996 film based on a true story of a town with a high concentration of cancer patients due to chemical leakage from a nearby chemical treatment facility. The selection of six films, including "A Civil Action", 
"Pelican Brief”, "Erin Brockovich”, “Whale Rider”, “An Inconvenient Truth”, and "Bhopal Express", covers a wide array of topics, but in the end, the plot is fundamentally about overcoming the disasters that follow unethical procedures.

\section{Sustainability in the Sophomore Engineering Clinic}

Rowan University's Engineering Clinic centers around engineering design and the development of communication skills, as shown in Table $1^{4}$. Throughout Sophomore Engineering Clinic, sustainability is a core theme. Sophomore engineering students work in multidisciplinary groups to develop their writing and speaking skills. A sample Sophomore Engineering Clinic II syllabus is available in Appendix B.

The Sophomore Clinic sequence is focused on engineering design, and for perhaps the first time in their undergraduate education, students are exposed to realistic design problems best solved by multidisciplinary engineering teams. Sustainability plays a key role in understanding the concepts required of these projects, and the importance of sustainable design is emphasized through lecture and project-based learning 5 . Notably, Sophomore Clinic has significant communication components, both written (fall semester) and oral (spring semester), and the course is team-taught with Communication faculty of Rowan University. Whenever possible, students write about and give speeches related to their engineering work, and student work is assessed by both Communication and Engineering faculty ${ }^{5}$.

Sophomore Engineering Clinic has evolved in recent years to incorporate sustainable design in a number of available projects that require students to develop imaginative solutions to environmental issues. These include projects such as developing and writing EPA grants, constructing wind turbines, and growing microalgae to harvest oil for biofuel.

\section{$\underline{\text { EPA Grant }}$}

In one Sophomore Engineering Clinic I project, students are required to develop and write about sustainable design through an Environmental Protection Agency (EPA) grant writing assignment. The EPA strives to protect human health and the environment through pollution reduction, environmental education, and environmental laws. Therefore, they created a grant called "P3", which stands for "People, Prosperity, and Planet", in order to encourage student research in sustainable engineering. A four-week time period of Sophomore Clinic I is dedicated to the P3 grant assignment. The lectures during this time range from how to write an effective research proposal, key features and attributes that a sustainable design solution should include, environmental remediation and treatment technology, and budget preparation guidelines. This assignment allows students to develop a research plan to improve society through a healthier population, a stimulated economy, and a greener planet.

\section{$\underline{\text { Wind Turbine Construction }}$}

Wind is an abundant domestic resource that can help meet the national need for an alternative energy source that is renewable and does not have damaging environmental effects ${ }^{6}$. Wind is a form of energy, combining the effects of the warmed atmosphere, the rotation of the earth, and the inequities of the earth's surface ${ }^{6}$. Wind power is harnessed by wind turbines. These turbines 
take the wind's kinetic energy and turn it into mechanical power. This energy can be used directly to turn grinders or to pump water, or it can be directed to a generator to convert into electricity ${ }^{8}$. These are the underlying motivations for the wind turbine project in the Sophomore Engineering Clinic sequence. In this project, students are given the opportunity to design a wind turbine to optimize power output under a list of given parameter specifications. The main project goal is to optimize a wind turbine that would produce the highest coefficient of power while addressing environmental and economic concerns. Students are given a limited supply of materials to encourage the efficient allocation of resources, reinforcing the economical considerations of sustainability. Figure 4 shows Rowan undergraduate students assembling their group wind turbine. Figures 5 and 6 show a final wind turbine designed by a team of Rowan undergraduate students being tested for power output.

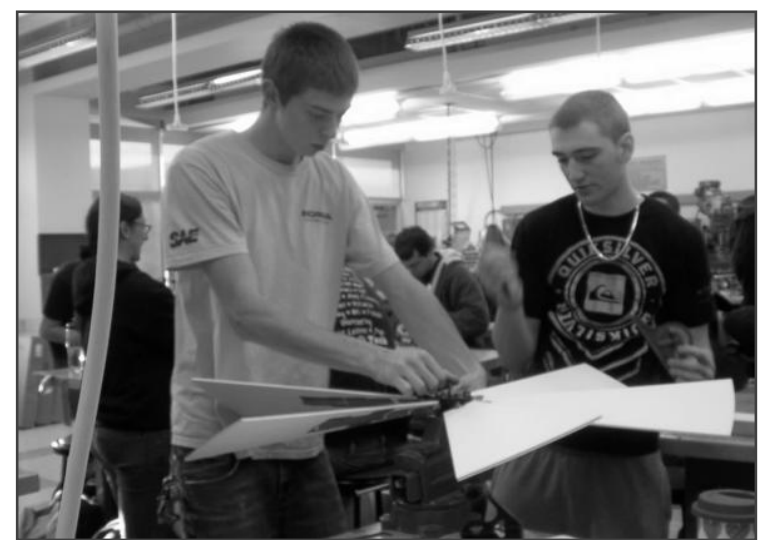

Figure 4: Rowan Undergraduate Students Constructing a Wind Turbine ${ }^{7}$

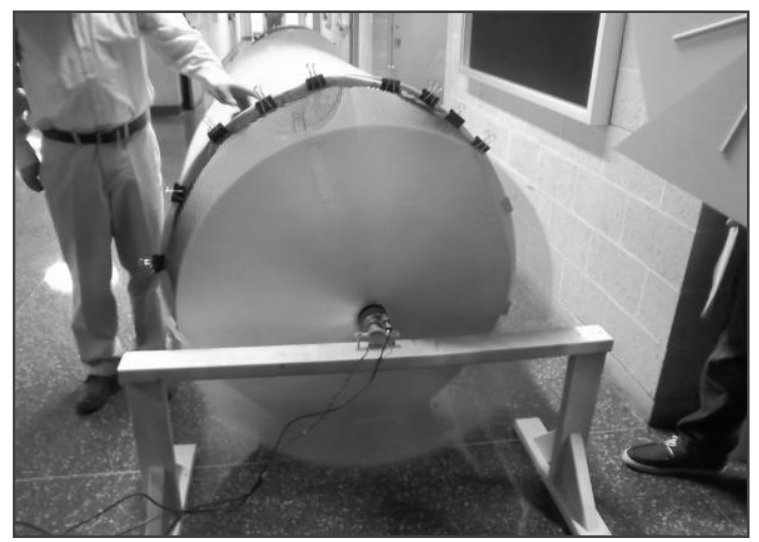

Figure 5: Rowan Engineering Faculty Testing a Student-Made Wind Turbine ${ }^{7}$

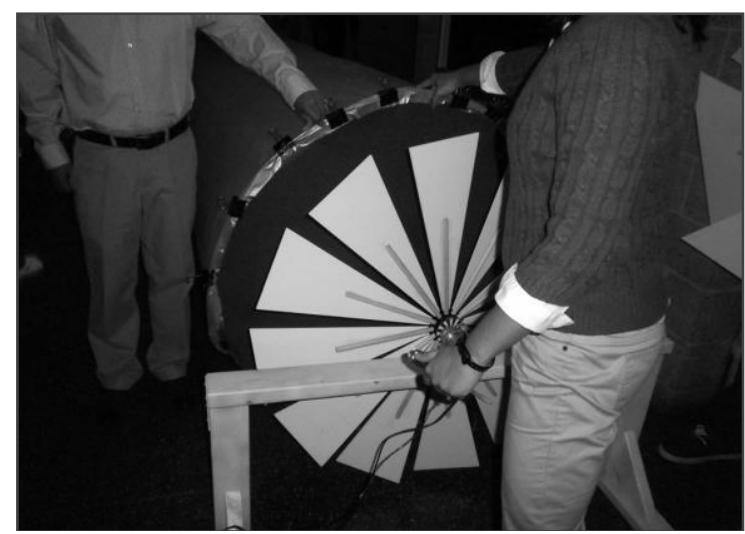

Figure 6: Rowan Undergraduate Students Preparing to Test a Wind Turbine ${ }^{7}$

\section{$\underline{\text { Algae-Derived Biofuel Production }}$}

Sophomore Engineering Clinic students at Rowan University have the opportunity to work on a project which looks into one of the most promising alternatives to traditional petroleum-based fuel: algae. 
Biofuels, specifically derived from algal species, are being strongly considered as a new energy source. According to studies, algae produce more oil per U.S. cropping area than many other oil crops $^{9}$. Lipids produced in microalgae are extracted and used for oil production. Algae produce lipids that are unsaturated, and therefore, require little to no pretreatment before transformation into biodiese ${ }^{10}$. Biodiesel fuel is currently made from plant and animal oils such as soybeans, corn, canola oil, and animal fat; all of which are materials that need to be replenished through farming. The problem is that in order to displace all transport fuel consumed in the United States, the land area required to grow these oil crops would be unsustainably large and interfere with food production.

In Sophomore Engineering Clinic, the practicality of using algae as an alternative to traditional biodiesel fuel materials is being studied extensively to optimize growth and oil extraction conditions. Some of the microalgal cultures being grown at Rowan University are shown in Figure 7. Setups for algal growth experiments are shown in Figures 8 and 9. During upper-level Engineering Clinic courses, students also have the opportunity of continuing their work on microalgal studies.

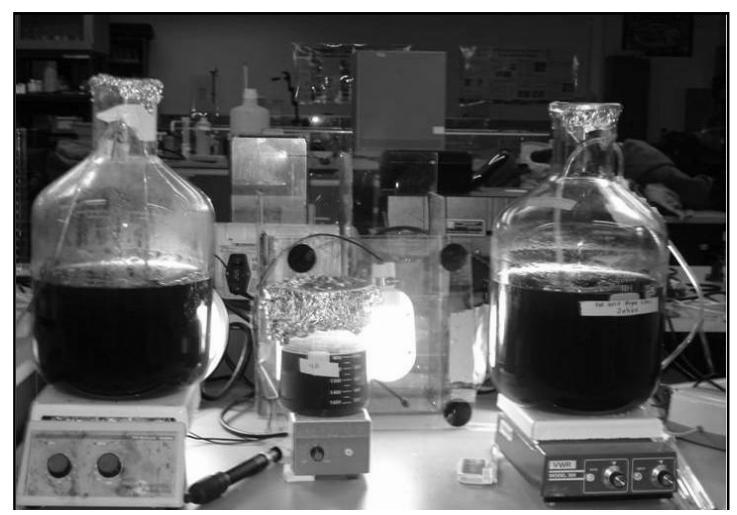

Figure 7: Microalgal Cultures Grown in Rowan University Laboratories ${ }^{7}$

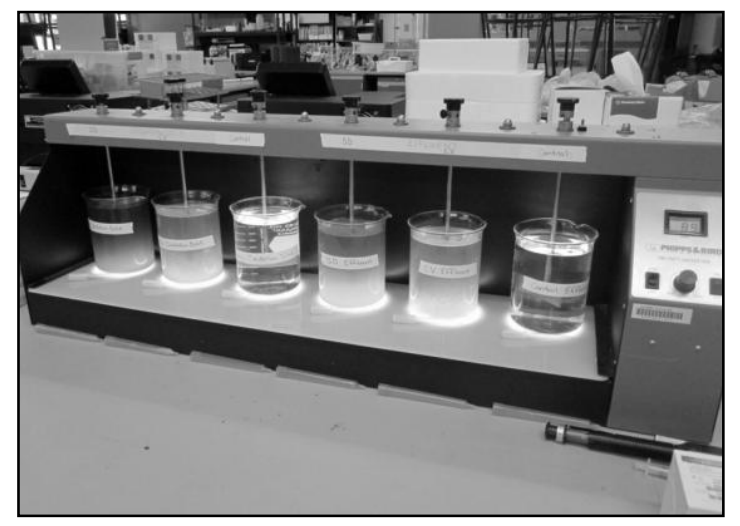

Figure 8: Microalgal Experiments Performed by Rowan Undergraduate Students $^{7}$

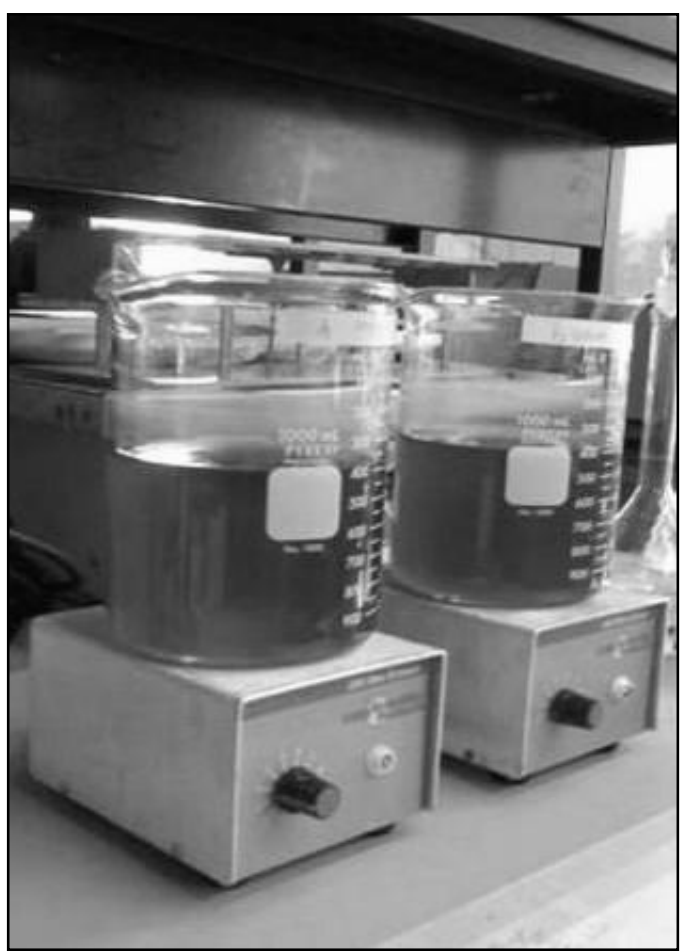

Figure 9: Microalgal Growth Studies Performed by Rowan Undergraduate Students 
While the sustainable engineering projects in the Freshman and Sophomore Engineering Clinic sequences have been highlighted, it is important to note that students also have the opportunity to continue research in projects relating to sustainable engineering during the Junior and Senior Engineering Clinic sequences. In these courses, Junior and Senior level students work in small teams (2-5 students) on open-ended projects under the supervision of one or more Engineering professors. Each team works on a unique project, which can be multiple semesters in length. Over 60 projects are run in a typical semester, and many are related to sustainable engineering ${ }^{5}$.

An example of a Junior and Senior Engineering Clinic project that encourages an environmentally-friendly alternative to cooking with wood fuel is the peanut shell briquette project. The purpose of this project is to provide an expense-free fuel to the people of Gambia, Africa, who are struggling with the rising cost of wood, because of extreme deforestation. Another Junior and Senior Engineering Clinic project that emphasized sustainability was the energy audit project. During this project, undergraduate students learned how to conduct energy audits like a professional energy auditor by studying the power output of each building on Rowan University's campus. After the students completed their energy audit, they made recommendations that could save the university thousands of dollars and reduce tons of greenhouse gas emissions from the university's most inefficient buildings. A third example of a Junior and Senior Engineering Clinic project involving sustainable engineering is the design of a hollow fiber membrane photobioreactor. The goal of the photobioreactor project is to grow microalgae more efficiently to provide both maximum greenhouse gas mitigation and a source of biofuel feedstock production.

\section{Creation of "Powerville"}

"Powerville" is a compelling Junior and Senior Clinic project that engages students with video games as an educational tool. The "Powerville" project involves using a virtual environment in the form of a video game to teach undergraduate students about the advantages of sustainable energy and design. During this project, the Clinic team is working on developing a video game that compares the energy output and environmental impact of conventional power plants to those of sustainable power plants, such as those producing solar and wind power. The students conducted research to provide the video game users with the most realistic feel possible when analyzing sustainable energy as an alternative to conventional energy generation techniques. The ultimate purpose of this virtual environment video game is to increase the users' understanding of the social and environmental responsibility of sustainable engineering through the realistic stimulation.

\section{Engineers Without Borders}

One of the most sustainability-oriented projects in the Junior and Senior Clinic sequences is the Engineers Without Borders (EWB) project. EWB is a service organization that offers students an opportunity to utilize their knowledge and skills to solve real world problems in third world countries. The mission of EWB is to ensure technical integrity and foster social responsibility and global awareness. The projects of EWB improve the quality of life in the communities they 
serve by implementing sustainable engineering solutions. EWB projects at Rowan University are focused on reducing societal problems by implementing engineering projects within the communities such as providing clean drinking water, safe transportation, sanitation, and shelter, or establishing industry. Students travel to work on projects in places such as El Salvador, Honduras, Senegal, Thailand, and Gambia.

This small sampling of Junior and Senior Engineering Clinic projects shows how sustainability is integrated into project-based learning at Rowan University. The Junior and Senior Clinic sequence teaches students about engineering with social, economic, and environmental parameters.

\section{Rowan University Faculty Perspectives}

Teaching sustainable engineering to undergraduate students is part of an on-going effort by engineering faculty at Rowan University, with the goal of producing engineers capable of rational and ethical engineering design in an increasingly complex world. This includes lifetime learning and the development of skills in understanding and integrating social and environmental considerations into designed systems ${ }^{1}$. Faculty at Rowan University acknowledge that these skills will not be achieved instantaneously; however, even at a preliminary stage, it is apparent that, to the extent that sustainable engineering and industrial ecology can continue to draw on each other, both lifetime learning and skills in understanding societal needs will be strengthened. Interviews with Rowan University faculty involved in the Freshman and Sophomore Engineering Clinic courses indicate that they believe the Engineering Clinic sequence is an effective vehicle for teaching undergraduate students about sustainability at an early stage in their education and preparing them for either graduate school or industrial careers.

"During the first years of engineering when students are building their engineering skills, it is important to provide context and background to some of the sustainability issues surrounding us," says Mechanical Engineering professor Dr. Smitesh Bakrania"1 . "So, I make a conscious attempt at discussing these issues and some of the challenges that we are currently facing and those that we will be facing in the near future. This is done through complex discussions, videos, and homework assignments. Using the Wind Turbine Clinic activity, we discuss a potential solution where engineers play a critical role in addressing sustainability."11

Rowan University's College of Engineering exposes students to actual research and grant applications, therefore, preparing them for graduate school or future careers. Dr. Gautam Pillay, a Chemical Engineering professor at Rowan University, developed the curriculum for incorporating grant writing into the Sophomore Engineering Clinic sequence. Dr. Pillay says "Writing the EPA P3 proposal is unique in that nowhere else in the four-year Engineering Clinic sequence is a student required to write a formal research proposal to an actual federal Request for Proposals."12 Normally, students do not even consider research until graduate school.

Regardless of discipline, undergraduate engineering students tackle hands-on projects from Freshman through Senior year through the Engineering Clinic sequence. In the last two years of the Engineering Clinic sequence, multidisciplinary teams of Juniors and Seniors advance to solving real-world problems for industry. "What industry loves about this is that they have had a 
student who has solved similar problems during the last two years of clinic," said Dr. Robert Hesketh, Chair of the Department of Chemical Engineering at Rowan University ${ }^{13}$. "When they start work within that industry, they know what to do."13 "These individual honors are noteworthy and are no doubt a reflection of our multidisciplinary approach to engineering education that includes contributions from all programs in the college," said Dr. Steven Chin, Interim Dean of the College of Engineering at Rowan University ${ }^{13}$. The importance placed on technical and communication skills, along with the knowledge of sustainable practices, make Rowan University engineers a valuable asset for the region and the engineering profession. Having an opportunity to learn sustainable solutions and practices as undergraduate students prepares students for this in the future.

"The combination of scarcer resources, seven billion plus people on the planet, and rising quality of life, makes sustainability awareness and skills more important than ever. It is important to both careers and the quality of life of our children and grandchildren," says Civil and Environmental Engineering professor Dr. Jess Everett ${ }^{14}$. "My main regret is not incorporating more, earlier."14

While it is clear that the faculty of Rowan University is passionate and enthusiastic about sustainability education at Rowan University, the goal is to examine the impact of the faculty's pedagogical innovations on the students from the students' perspectives.

\section{Undergraduate Student Perspectives}

Pedagogical practices must evolve to address pertinent societal challenges, such as sustainability. The undergraduate students enrolled in Rowan University's College of Engineering feel that the Engineering Clinic sequence has helped faculty do just that. The hands-on and team-oriented activities of the Engineering Clinic sequence prepares undergraduate students for real-world projects and provide students with valuable experiences that give them advantages when applying for internships, scholarships, graduate school, and jobs after graduation. Often, Rowan University undergraduates can point to conference or journal publications, engineering reports, design and fabrication experience, or field work as evidence of their exceptional preparation for the real world. Anecdotal evidence and internship surveys from employers of Rowan University alumni support this.

The undergraduate authors of this paper have completed two years of the Engineering Clinic sequence themselves and have been active in the sustainable Clinic projects previously mentioned. They believe that through the Engineering Clinic sequence, engineers of the future are gaining a fundamental understanding of their role in the design and analysis of complex interacting systems, as well as discovering the importance of incorporating sustainability into engineering practice.

In personal interviews, other Rowan engineering students have reacted to the sustainability education movement in a positive way. John Grisi, a Sophomore student majoring in Mechanical Engineering, reflects upon his Freshman Engineering Clinic projects. During Freshman Engineering Clinic I, Grisi worked on calculating how much paper waste an individual person generates, and then how to creatively and easily reduce the waste quantity. During 
Freshman Engineering Clinic II, Grisi learned the basics of solar panel technology and studied the fundamentals of biodiesel to power cars. Grisi says "Every Freshman Clinic project I participated in had something to do with sustainability. As a Mechanical Engineering student, I thought I would not be exposed to sustainable design as in depth. I am really gaining a deeper understanding of how I, as an engineer, can impact the environment in a positive way.", Making students aware that every branch of engineering affects the environment has been a crucial concept of the sustainability curriculum at Rowan University. Regardless of the specific Clinic project, it is clear to the students that in every situation, negative environmental affects must be minimized.

While completing the Solar Panel Clinic project, students were encouraged to participate in hands-on interactions. Junior Civil and Environmental Engineering student Christopher Seigel says: "Our lectures were very interesting and helped every student grasp the theory and understanding needed to complete the project. However, the laboratory modules were crucial for understanding the basic concepts of solar panel design. We had to get our hands dirty to understand how deeply the project actually went. We had to identify every source of energy, analyze the whole system to determine how much energy is actually consumed, and how to reduce its costs. All that cannot be taught with only a simple lecture."16

When asked if he would be more likely to incorporate sustainable engineering into his projects outside of the classroom after completing the Solar Panel Clinic project, Seigel responded "Definitely. The Solar Panel Clinic taught me that the world's energy source is not something to take advantage of. Engineers must use energy wisely by incorporating green materials into their designs and being more aware of their carbon footprint."16

Sophomore Electrical and Computer Engineering student, Samantha Pfeiffer, reflects upon the Wind Turbine Clinic and its economic and environmental requirements: "Working on the Wind Turbine Clinic has made me more aware of what makes a project economically feasible and successful. Nowadays, projects must not only observe a specified budget, but are often expected to meet certain environmental requirements as well." 17 The Wind Turbine Clinic has helped increase understanding of making careful choices in the usage of materials, as well as the practicality of design.

The addition of a sustainable focus in the writing component of Sophomore Engineering Clinic was also appreciated. Sophomore Civil and Environmental Engineering student, Kassandra Grimes, provides feedback about the P3 grant proposal: "Being able to develop my own research plan as an undergraduate student was an opportunity I thought I would never have. Clearly, sustainability is crucial for society, and research in green engineering can present many opportunities for developing engineers."18

All companies, whether they are related to engineering or not, should be mindful of their environmental impact and the impact they have on society. Engineering ethics examines and sets the obligations of engineers to society, to their clients, and to the profession. Sophomore Electrical and Computer Engineering student, Thomas Goodman, comments about the ethical movie viewing project of Freshman Engineering Clinic II: "Ethics are a huge part of all careers. Being ethical as an engineer is just as important as being able to count as an accountant. It goes 
hand in hand with what engineers do."19 During this Clinic sequence, the social aspect of sustainability is stressed through ethical laboratory modules and film presentations about ethical issues.

According to the undergraduate students at Rowan University, the Engineering Clinic sequence has allowed the program to expand the development of ideas to now incorporate sustainable practice in engineering education. The Engineering Clinic sequence results in a number of benefits for undergraduate engineering students. They are introduced to hands-on activities that spark their interest in engineering and provide what is hopefully the beginning of lifetime learning in sustainable practices.

\section{Conclusions}

Through hands-on learning and innovative pedagogical methods, Rowan University's unique Engineering Clinic sequence teaches students how to incorporate sustainability into engineering projects, as well as daily life. Modules focused on EPA grant writing, wind turbine design, solar panel development, and algae-derived biofuel optimization bring the concepts of sustainability to reality as students explore the technicalities behind green engineering. The Engineering faculty at Rowan University is continually increasing their incorporation of sustainable design into the Engineering Clinic sequence; however, they caution that when teaching students about sustainable engineering, being practical is important: "The most important aspect is to consider the appropriateness of a sustainable solution," says Mechanical Engineering professor Dr.

Jennifer Kadlowec ${ }^{20}$. If students cannot picture how a solution can happen, it is harder for them to be able to develop a way to implement the solution. With hands-on projects, Rowan University's Engineering Clinic sequence shows students how sustainable engineering can also be practical.

By conducting undergraduate interviews, it was clear that through the Engineering Clinic sequence, students gained not only a basic understanding of sustainability, but also an understanding of how to apply it in practice. Furthermore, they have become engaged in lifelong learning and advocacy in sustainable engineering practices. Junior Civil and Environmental Engineering student Christopher Seigel says "People, especially engineers, need to be more aware of sustainable or green engineering and how it can be incorporated into society in a practical manner. More people need to be aware of and need to care more about the environment and their surroundings, or we will never be able to resolve our pressing societal needs.",16

\section{References}

1. Allenby, B. R.; Allen, D. T.; Davidso, C. I. (2007) Teaching Sustainable Engineering, J. Ind. Ecol., 11 (1).

2. Huntzinger, D. N.; Hutchins, M. J.; Gierke, J. S.; Sutherlan, J. W. (2007) Enabling Sustainable Thinking in Undergraduate Engineering Education, Int. J. Engng Ed., 23 (2), 218-230.

3. Perdan, S.; Azapagic, A.; Clift, R. (2000) Teaching Sustainable Development to Engineering Students, Int. J. Sustain. High. Educ., 1 (3), 267-279. 
4. Rowan University's Official Website (2011) College of Engineering Official Website, available at: www.Rowan.edu/colleges/engineering/programs (accessed November 2011).

5. Everett, J.; Newell, J.; Dahm, K.; Kadlowec, J.; Sukumaran, B. (2004) Engineering Clinic: Bringing Practice Back into the Engineering Curriculum, Engineering Education Conference, University of Wolverhampton, England, U.K.

6. Energy Sources (2009) U.S. Department of Energy, Washington, D.C., available at: www.energy.gov/energysources/wind (accessed November 2011).

7. Bauer, S. (2010-2011) Photograph, Rowan University, Glassboro, N.J.

8. Wind \& Hydropower Technologies (2009) U.S. Department of Energy, Washington, D.C., available at: www.eere.energy.gov/windandhydro (accessed November 2011).

9. Chisti, Y. (2007) Biodiesel from Microalgae. Biotechnol. Adv. 25, 294-306.

10. Woertz, I. C. (2007) Lipid Productivity of Algae Grown on Dairy Wastewater as a Possible Feedstock for Biodiesel. California Polytechnic U., Dept. of CEE, 1-75.

11. Bakrania, S. (2 January 2012), Email Interview.

12. Pillay, G. (20 December 2011), Email Interview.

13. Quigley, P. (2011) Engineering News, College of Engineering Newsletter, 8 (1), available at: www.Rowan.edu/colleges/engineering/newsletter/downloads/fall_2011_newsletter.pdf (assessed November 2011).

14. Everett, J. (21 December 2011) Email Interview.

15. Grisi, J. (20 December 2011), Personal Interview, Rowan University, Glassboro, N.J.

16. Seigel, C. (20 December 2011), Personal Interview, Rowan University, Glassboro, N.J.

17. Pfeiffer, S. (2 March 2012), Personal Interview, Rowan University, Glassboro, N.J.

18. Grimes, K. (20 December 2011), Personal Interview, Rowan University, Glassboro, N.J.

19. Goodman, T. (2 March 2012), Personal Interview, Rowan University, Glassboro, N.J.

20. Kadlowec, J. (20 December 2011), Email Interview. 


\section{Appendix A: Freshman Clinic II Sequence Syllabus FRESHMAN ENGINEERING CLINIC II - SPRING 2011}

\section{Competitive Assessment}

In today's quickly changing and increasingly competitive market place, it is imperative that manufacturers keep abreast of the technological advances and design innovations incorporated into competing product lines. The term competitive assessment, or reverse engineering, has been coined by manufacturers to describe the process of ethically acquiring, inspecting, analyzing, instrumenting, and testing the product lines of other manufacturers. You will be required to use the skills obtained in Freshman Engineering Clinic I. Developing engineers with hands-on practice is critical to the economic development of the U.S. industry.

\section{Technical Objectives}

1) Introduce students to the science and art of design by evaluating the work of practicing designers,

2) Introduce multidisciplinary teams of engineering students to unifying engineering science principles, such as mass, momentum and energy balances, materials, thermodynamics, and electricity and magnetism, using a consumer appliance or an engineering process as a test bed,

3) Enable students to determine how scientific principles, material properties, manufacturing techniques, cost, safety requirements, environmental considerations, and intellectual property rights impact the design of a product,

4) Allow students to participate actively in a meaningful design effort by instrumenting and evaluating the performance of a consumer appliance, product, or an engineering process,

5) Develop technical communication skills in graphical, written, and oral formats, and

6) Continue development of time management, and critical thinking skills. 


\section{Appendix B: Sophomore Clinic II Sequence Syllabus \\ SOPHOMORE ENGINEERING CLINIC II - SPRING 2011}

Catalog Description

This course, the fourth in the eight-semester engineering clinic series, provides expanded treatment of the practice of engineering through applications drawn from engineering disciplines and industry. The communication component is designed to help students prepare and present messages in public speaking contexts. In addition to engineering design, the course emphasizes oral presentation skills, as well as critical thinking, listening, and organizations skills.

\section{Course Goals}

The two main goals of Sophomore Engineering Clinic II are to provide the foundation necessary for students to become effective engineering communicators and designers.

Accordingly, during the semester, each student will complete one or more design projects. As in all engineering design projects, oral and technical communication is integrated throughout.

\section{Technical Objectives}

After successful completion of this course, all Rowan Engineering students will be able to:

- Research, design, and deliver an effective, informative, technical, and persuasive speech.

- Adapt technical information to a non-technical audience.

- Adapt speech content and delivery based on audience analysis.

- Recognize the different purposes and structures of informative and persuasive speeches.

- Synthesize and incorporate research for use in individual and group oral presentations.

- Recognize and utilize effective visual aids for presentations, as well as graphical strategies for communicating information in reports.

- Recognize the need, identify the customer, assess the market, and define the goals, objectives, and constraints for a design problem.

- Generate multiple engineering design solutions using various brainstorming techniques.

- Perform appropriate engineering analyses and choose the optimal solution based on these results.

- Apply technical writing skills effectively to describe and validate design decisions.

*Adapted from Rowan University's College of Engineering Official Course Website 4 